\title{
Göğüs ağrısı olan mitral kapak prolapsuslu çocuk hastalarda gastroözofageal reflü birlikteliği
}

\author{
Association of gastroesophageal reflux and chest pain in children with mitral valve prolapse
}

\author{
Serkan Fazlı ÇELIK , Eylem SEVINÇ², Elif ÇELIK ${ }^{3}$, Erkan DOĞAN ${ }^{4}$ \\ Adnan Menderes Üniversitesi Tıp Fakültesi, 'Çocuk Kardiyolojisi Bilim Dalı, ${ }^{3}$ Çocuk Sağlığı ve Hastalıkları Anabilim Dalı, Aydın \\ Karabük Üniversitesi Tıp Fakültesi, ${ }^{2}$ Çocuk Gastroenterolojisi Bilim Dalı, ${ }^{4}$ Çocuk Sağlığı ve Hastalıkları Anabilim Dalı, Karabük
}

\begin{abstract}
Giriş ve Amaç: Göğüs ağrısı ve mitral kapak prolapsusu olan çocuklarda fonksiyonel gastrointestinal hastalıkların göğüs ağrıııla ilişkisini araştıran az sayıda çalışma vardır. Bu çalışmada mitral kapak prolapsusu olan çocuklarda göğüs ağrıı ve gastroözofageal reflü hastalı̆̆ı arasındaki ilişkiyi tanımlamayı amaçladık. Gereç ve Yöntem: Çalışmaya, tipik üst gastrointestinal sistem semptomları ve göğüs ağrıı tanımlayan, hafif ile orta mitral kapak prolapsusu olan 70 çocuk hasta dahil edildi. Hastalar sekiz hafta süreyle anti-reflü ilaç tedavisi ile tedavi edildi. Tedaviden önce ve sonra hastalar gastroözofageal reflü hastalığı etki ölçeği ile değerlendirildi. Bulgular: Hastaların yaş ortalaması 13.24 2. 81 yıldı ve 42 'si (\%60) kızdı. 30 hastanın semptomları 6 haftadan daha fazla ve 40 hastanın semptomları 6 haftadan az süredir mevcuttu. Tüm hastaların ortalama semptom süresi $8 \pm 2.2$ haftaydı. En çok bildirilen semptom göğüs ağrısı (\%89.9) ve ardından regürjitasyon (\%50) idi. Kronik gastroözofageal reflü olan çocuklarla karşılaştırıldığında, yeni gastroözofageal reflü tanısı alan çocuklarda anlamlı olarak daha sık ve ciddi semptomlar vardı. Mitral kapak prolapsusunun şiddeti ile semptomlar arasında anlamlı bir ilişki bulunmadı. Gastroözofageal reflü hastalığı etki ölçeği skorları, tedaviden sonra tüm hastalarda istatistiksel olarak azalmıştı ( $p$ <0.01). Her iki hasta grubu tedaviden fayda sağlasa da, gastroözofageal reflü hastalı̆ı yeni saptanan hastalar, kronik hastalardan daha fazla tedaviden fayda gördüler. Sonuç: Mitral kapak prolapsusu ve göğüs ağrısı olan birçok çocuk hastada semptomatik gastroözofageal reflü hastalığı mevcuttur. Gastroözofageal reflünün spesifik tanısı ve tedavisi çoğu hastada göğüs ağrısını hafifletmiştir.
\end{abstract}

Anahtar kelimeler: Mitral kapak prolapsusu, reflü, göğüs ağrısı, çocuklar

\section{Giris}

Çocukluk çağında göğüs ağrısının kardiyak nedenli olma intimali erişkinlerden daha azdır (1). Göğüs ağrısı olan çocuklarda rutin oskültasyon veya elektrokardiyografide anormal bir bulgu saptandığında bir pediyatrik kardiyolog tarafından değerlendirilmesi önerilir (2). Göğüs ağrısı ile ilişkili olduğu bilinen en yaygın kardiyak hastalık ise mitral kapak prolapsusudur (MVP). Ağrı mekanizması belirsizdir ve MVP'nin çocuklarda çok sık göğüs ağrısı nedeni olması

\footnotetext{
Illetişim: Serkan ÇELIK

Adnan Menderes Üniversitesi Tıp Fakültesi, Çocuk Kardiyolojisi Bilim Dalı,

Efeler Kampüsü, Aydın

E-mail: docser2003@yahoo.com
}

Background and Aims: To date, few studies have investigated the association of pediatric functional gastrointestinal diseases with mitral valve prolapse and chest pain. We aimed to describe the relationship between chest pain and gastroesophageal reflux disease in children with mitral valve prolapse. Materials and Methods: This study included 70 pediatric patients with mild-to-moderate mitral valve prolapse with complaints of typical upper gastrointestinal system symptoms and chest pain. The patients were treated with medical anti-reflux drug therapy for 8 weeks. Before and after treatment, the patients were assessed with the Gastroesophageal Reflux Disease Impact Scale. Results: The mean patient age was $13.24 \pm 2.81$ years, and 42 (60\%) patients were female. The duration of symptoms in 30 patients was longer than 6 weeks, and that of 40 patients was shorter than 6 weeks. The mean symptom duration of all patients was $8 \pm 2.2$ weeks. The most frequently reported symptom was chest pain (89.9\%), followed by regurgitation (50\%). Compared with children who had chronic gastroesophageal reflux, children with recent, acute gastroesophageal reflux reported significantly more frequent and severe symptoms. There was no significant relationship between the severity of mitral valve prolapse and symptoms. Gastroesophageal Reflux Disease Impact Scale scores of all patients were significantly decreased after treatment $(p<0.01)$. Although both groups of patients benefited from treatment, it was found that patients with newly diagnosed gastroesophageal reflux disease benefited significantly more from treatment than patients with chronic disease. Conclusion: Many preadolescents and adolescents with mitral valve prolapse and chest pain had symptomatic gastroesophageal reflux disease. Specific diagnosis and therapy for gastroesophageal reflux disease alleviated chest pain in most patients.

Key words: Mitral valve prolapse, reflux, chest pain, children

beklenmez (\%0-4) (1). MVP'li erişkinlerde diğer bir göğüs ağrısı nedeni olan gastroözefageal reflü (GÖR)'nün normal popülasyona göre daha yaygın olduğu iddia edilmiştir (3). MVP'si ve göğüs ağrısı olan çocuk hastalarda ise ne yazık ki GÖR'ün göğüs ağrısı üzerine etkisini araştıran fazla çalışma yoktur. Bu nedenle MVP'si ve ğöğüs ağrısı olan çocuk hastalarda daha sık göğüs ağrısı nedeni olan GÖR'ün göğüs ağrısı üzerine etkisi araştııldı.

Çelik SF, Sevinç E, Çelik E, et al. Association of gastroesophageal reflux and chest pain in children with mitral valve prolapse. The Turkish Journal of Academic Gastroenterology 2019;18:2-6. DOI: 10.17941/agd.543443

Geliş Tarihi: 26.02.2018 • Kabul Tarihi: 23.02.2019 
GÖR tanısında tipik reflü semptomları (mide ekşimesi ve/ veya regürjitasyon gibi) varlığında teşhis için ileri testlere gerek olmadığı öneriler arasındadır $(4,5)$. Klinikte, proton pompa inhibitörleri (PPI) ile ampirik asit baskılama tedavisi, GÖR hastalarında ilk tedavi olarak kabul edilir (6).

Bu çalışmada tipik üst gastrointestinal sistem semptomları ve göğüs ağrısı tarifleyen, hafif veya orta derecede MVP'si olan çocuk hastalara, medikal tedavi öncesi ve tedavinin sekizinci haftasında Gastroözofageal Reflü Hastalığı Etki Ölçeği (GÖRHEÖ) (7) ile değerlendirme yapılarak, bu hastalarda göğüs ağrısı ile gastroözofageal reflü arasındaki ilişkinin tespit edilmesi amaçlanmışır.

\section{GEREÇ ve YÖNTEM}

\section{Çalışma ve Kontrol Grubu}

$\mathrm{Bu}$ prospektif çalışmaya, hastanemiz pediyatrik kardiyoloji ve pediyatrik gastroenteroloji bölümünde, Şubat 2016-Şubat 2017 tarihleri arasında takip edilen tipik gastrointestinal sistem semptomları ve göğüs ağrısı tarifleyen hafif/orta derecede MVP tanısı olan 85 çocuk hasta dahil edildi. Hastalardan ve ailelelerinden yazılı onam alınarak, hastalara oral 1-1,5 mg/kg/gün proton pompa inhibitörü (PPI) lansoprazol başlandı, yüz yüze görüşme ile tedavi öncesi ve tedavinin sekizinci haftasında adölesanlarda kolayca uygulanabilen GÖRHEÖ ile değerlendirme yapıl- dı (Tablo 1). Son 1 hafta içinde, hiç şikayet olmaması 1 puan, ara sıra olması 2 puan, sık sık olması 3 puan ve her zaman olması 4 puan olarak değerlendirilip, puanlar toplanarak toplam skorlar elde edildi.

Hastalar tedaviye yanıtlarına göre ileri tetkik ve tedavi amacıyla Pediyatrik Gastroenteroloji Bölümüne yönlendirildi. Çalışmaya alınma kriterleri; hastaların MVP dışında ek kardiyak problemlerinin olmaması ve herhangi bir kardiyak ya da ek bir hastalığa bağlı herhangi bir ilaç tedavisi almamaları, 8. hafta sonundaki takiplerine gelmeleri ve reçete edilen PPI düzenli almaları olarak belirlenmiştir. Çalışmayla ilgili etik kurul onayı 2016 yılı Karabük Üniversitesi Etik Kurul (sayı no:13941) ile eğitim planlama kurulundan alınmışır.

\section{İstatistiksel Analiz}

Niceliksel parametrik veriler ortalama \pm standart sapma olarak belirtildi. Niceliksel parametrik olmayan veriler medyan olarak ifade edildi. Mann-Whitney ve Kruskall-Wallis testleri medyanları karşılaştırmada kullanıldı. Korelasyon testlerinden Spearmen korelasyon testi parametrik olmayan veriler için, Pearson korelasyon testi parametrik veriler için kullanıldı. Nitel veriler frekans (sıklık) olarak ifade edilip, yüzde olarak verildi. P değerinin 0,05 nin altında olması anlamlı olarak kabul edildi. Veri yönetimi ve analizi için SPSS 15.0 windows (SPSS Inc., Chicago, IL, ABD) kullanıldı.

\section{Tablo 1. Gastroözofageal reflü hastalığı etki ölçeği}

1. Son 1 hafta içinde göğsünüzde ağrı hissi oldu mu?

2. Son 1 hafta içinde göğsünüzde yanma hissi oldu mu?

3. Son 1 hafta içinde mide içeriğinizin boğazınıza veya ağzınıza geldiğini fark ettiniz mi?

4. Son 1 hafta içinde boğazınızda yanma hissi oldu mu?

5. Son 1 hafta içinde mide ekşimesi, mide içeriğinizin boğazınıza veya ağzınıza gelmesine bağlı boğaz ağrısı veya ses kısıklığınız oldu mu?

6. Son bir hafta içinde ağrılar veya mide içeriğinizin boğazınıza, ağzınıza gelmesinden dolayı hiç uyumakta zorlandınız mı?

7. Son bir hafta içinde şikayetleriniz nedeniyle hiç sevdiğiniz herhangi bir içeceği veya yiyeceği tüketmeden kaçındınız mı?

8. Son bir hafta içinde şikayetleriniz nedeniyle günlük işlerinizden hiç geri kaldınız mı?

9. Son 1 hafta içinde doktorunuzun reçete ettiği ilaçlar dışında ağrıdan dolayı veya mide içeriğinizin boğazınıza veya ağzınıza gelmesinden dolayı farklı bir ilaç ya da içecek, yiyecek almak istediniz mi? 


\section{BULGULAR}

Hastaların yaş ortalaması 13,24 $\pm 2,81$ yıl (minimum: 12,5, maksimum 17,5 yıl) ve 42'si (\%60) kızdı. Tedavi başlangıcından 8 hafta sonra kontrole gelmeyen 15 hasta çalışmadan çıkarılarak toplam 70 hasta ile çalışma bitirildi. Çalışma grubunda şikayetleri 6 haftadan daha uzun olan 30 ve 6 haftadan daha az süredir olan 40 hasta mevcuttu. Çarpıntı, kolay yorulma ve anksiyete göğüs ağrısı ile ilişkili semptomlardı. Yedi hastada (\%10) ağrı aktivite ile şiddetlenmekteydi. Kardiyak oskültasyonda, hastaların \%97,3'ünde mid-sistolik klik mevcuttu. Tüm hastaların ortalama semptomların süresi $8 \pm 2,2$ haftaydı. Tedavi öncesine göre sonrasında tüm hastaların GÖRHEÖ skorları $(13,73 \pm 3,21$ ve $8,11 \pm 1,54 ; p<0,01)$ ve semptomlarının süresi $[2,8(2,3)$ gün ve $1,1(0,9)$ gün $p<0,01]$ istatiksel olarak anlamlı oranda azalmıştı (Tablo 2). Kronik GÖR şikayetleri olan hastalar ile karşılaştıııldığında, tedavi öncesi yeni başlangıçlı GÖR şikayetleri olan hastalarda anlamlı olarak daha sık $[3,1(2,8)$ gün ve $1,9(1,5)$ gün; $p<0,01]$ ve daha şiddetli semptomlar bildirdiler $(16,31 \pm 5,35$ ve $11,21 \pm 1,21 ; p<0,03)$. Her iki hasta grubu da tedaviden fayda görmekle beraber, yeni GÖR hastalarının semptomlarının şiddetindeki azalma daha fazla idi $(8,85 \pm 2,44$ ve 7,66 $\pm 1,54 ; p<0,04$ ) (Tablo 3). Anti asit tedavisinden hiç fayda görmeyen ve çocuk gastroenteroloji bölümü tarafından değerlendirilen üç kız hastaya oral beta bloker (Propranolol, 1 mg/kg/gün) başlandı. Bu üç hastada da ağrının aktivite ile şiddetlendiği tespit edildi.

\begin{tabular}{|c|c|c|c|}
\hline & Tedavi Öncesi & Tedavi Sonrası & $p$ \\
\hline Yaş (ort.) (minumum-maksimum, yıl) & $13,24 \pm 2,81(12,5-17,5)$ & $13,44 \pm 3,1(12,7-17,9)$ & 0,90 \\
\hline Cinsiyet (E/K) & $28 / 42$ & $28 / 42$ & - \\
\hline Kilo (kg) & $50,9 \pm 2,3$ & $51,2 \pm 2,4$ & 0,54 \\
\hline Boy $(\mathrm{cm})$ & $153,4 \pm 4,1$ & $154 \pm 4,4$ & 0,61 \\
\hline Semptomların süresi (hafta) & $8 \pm 2,2$ & - & \\
\hline GÖRHEÖ puanı (ortalama $\pm S D$ ) & $13,73 \pm 3,21$ & $8,11 \pm 1,54$ & $<0,01$ \\
\hline Semptomların sıklığı [ortalama (sd) gün, geçen 2 hafta] & $2,8(2,3)$ & $1,1(0,9)$ & $<0,01$ \\
\hline
\end{tabular}

GÖRHEÖ: Gastroözofageal reflü hastalığı etki ölçeği.

Tablo 3. Yeni ve kronik GÖR hastalarının antropometrik değerleri, gastroözofageal reflü hastalığı etki ölçeği puanı, tedavi öncesi ve sonrası semptom sıklık, süre ve şiddetleri

\begin{tabular}{|lccc}
\hline & Kronik GÖR (n:30) & Yeni GÖR Hastaları (n:40) & $\mathbf{p ~}$ \\
\hline Yaş & $14,21 \pm 3,01$ & $13,11 \pm 2,54$ & 0,82 \\
\hline Cinsiyet (E/K) & $12 / 18$ & $16 / 24$ & 0,52 \\
\hline Kilo (kg) & $51,4 \pm 2,4$ & $50,6 \pm 2,3$ & 0,58 \\
\hline Boy (cm) & $154,5 \pm 4,5$ & $152,3 \pm 3,9$ & 0,42 \\
\hline Tedavi öncesi GiS skoru & $11,21 \pm 1,21$ & $16,31 \pm 5,35$ & $<0,03$ \\
\hline Tedavi sonrası GÖRHEÖ skoru & $8,85 \pm 2,44$ & $7,66 \pm 1,54$ & $<0,04$ \\
\hline Tedavi öncesi -semptomların sıklığı [ort (sd) gün/ son 1 hafta] & $1,9(1,5)$ & $3,1(2,8)$ & $<0,01$ \\
\hline Tedavi sonrası -semptomların sıklığı [ort (sd) gün/ son 1 hafta] & $1,6(1,3)$ & $0,4(0,2)$ & $3 \pm 1,4$ \\
\hline Semptomların süresi (son 1 hafta) & $14 \pm 6,1$ & $<0,01$ \\
\hline Semptomların şiddeti $n$ (\%) & & $22(22)$ & $<0,01$ \\
\hline Hafif & $58(54)$ & $56(56)$ & $5(5)$
\end{tabular}

GÖR: Gastroözofageal reflü. GiS: Gastrointestinal sistem. GÖRHEÖ: Gastroözofageal reflü hastalığı etki ölçeği. 


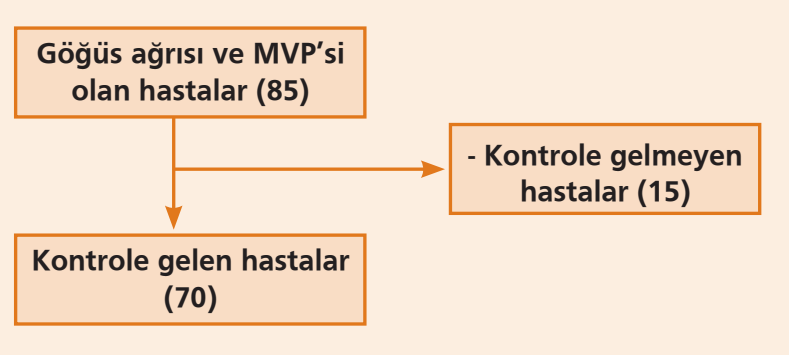

Şekil 1. Çalışmanın tasarımı.

\section{TARTISSMA}

Mitral kapak prolapsusu ve göğüs ağrısı olan çocuk hastalarda yapılan bu çalışma, kardiyak kökenli ağrıları taklit eden göğüs ağrılarının sıklıkla GÖR kaynaklı olduğunu ve uygun tedavi ile göğüs ağrısı şikayetlerinin gerilediğini ortaya koymuştur.

Çocukluk ve ergenlik döneminde göğüs ağrısı yaygın görülen bir semptomdur, ancak bu ağrıların kardiyak nedenli olma olasılığı \%4'den azdır (7). Fox ve ark., yaptıkları çalışmalarında erişkin hastalarda kardiyak nedenli olmayan göğüs ağrılarının en sık nedeninin gastroözefageal reflü hastalığı olduğunu bildirmişler (8). Benzer sonucu Sabri ve ark. çocuklarda göğüs ağrısının nedenlerini araştırdıkları çalışmalarında saptamışlardır (9). Fyfe ve ark., pozitif oskültasyon bulgularının varlığı ve göğüs ağrısı şikayetleriyle başvuran çocuk hastalarının sadece \%6'sını çocuk kardiyoloji kliniğine yönlendirmişler (2) ve bu çocukların \%70'inin masum üfürümü olduğu, geri kalan \%30'unda ise kardiyak bir problem olduğu saptanmış ve bunların da 1/3'ünde MVP tespit edilmesine rağmen bu hastalarda da göğüs ağrılarının kardiyak kökenli olmadığını bildirmişlerdir. Yetişkinlerde MVP'ye bağlı göğüs ağrısı insidansı \%50'ye kadar çıkabilirken (1), çocuklarda bu oran çok daha düşüktür (\%1 ile \%18 arasında) (10).

Hasta grubumuzun anti asit tedavisine anlamlı yanıtı \%95,8 gibi çok yüksek bir değerdedir. Sabri ve ark., göğüs ağrısı olan 44 hastanın \%93,2'sinde epigastrik hassasiyete özefajit, gastrit, duodenit ve gastroduodenitin neden olduğunu göstermişlerdir (9). Üstelik bu hastalar, çalışmamızdaki bulgulara benzer şekilde anti asit tedavisine çok iyi yanıt vermişlerdir. Yine Woolf ve ark., göğüs ağrısı tarifleyen MVP'li 17 çocuk hastanın 14 tanesinde ileri tetkikler ile üst gastrointestinal sistem problemleri (hastaların 5 tanesinde özofajit, 5 tanesinde gastrit, 1 tanesinde yüksek amplitüdlü özofageal kontraksiyon, 2 tanesinde özofageal reflü ve 1 tanesinde de pozitif Bernstein testli anormal özofageal basınç) saptamışlardır (1). Benzer şekilde, Hammet ve ark. MVP'si olan erişkin hastaların özofageal dismotilitelerinin daha fazla olduğunu ve bu hastaların asite karşı daha hassas olduklarını iddia etmişlerdir. Ne yazık ki bu konuda çocuklarda yapılmış herhangi bir çalışmaya literatürde rastlanmamıştır (11).

Gastroözefageal reflü tanısı koymak için birçok yöntem var olup, hastaların tespit edilmesine yönelik anketlerin kullanımı kolay ve düşük maliyetler nedeniyle tercih edilmektedir (12). Bu konuda farklı anketler olmasına rağmen, çocukluk çağına özgü uyarlanmış bir anket bulunmamaktadır. Gastroözofageal Reflü Hastalığı Etki Ölçeği, gastroözefageal reflü semptomlarının yaşam kalitesi üzerine etkisini değerlendirmeyi amaçlamıştır (13). Çalışmada kullanılan ölçeğin, yeni tanı konulmuş gastroözofageal reflü veya tedavi görmekte olan hastalarda psikometrik özellikleri değerlendirmedeki başarısı ve birinci basamak hastaları yönetmedeki etkisi daha önce de gösterilmiştir $(7,13)$. Biz de bu skalayı GÖR tanısı ve tedaviye cevabı saptamada kullandık.

MVP'nin şiddeti ile semptomlar arasında anlamlı bir ilişki saptanmamıştır. Tedavi öncesine göre tedavi sonrasında tüm hastaların GÖRHEÖ skorları ve GÖR semptomları istatiksel olarak anlamlı azalmıştır. Hastalarımızdan yeni GÖR olanlar, kronik GÖR hastalarına göre tedavi öncesi istatiksel olarak anlamlı derecede daha sık ve şiddetli semptomlar bildirmişlerdir. Tedaviden hastalarımızın büyük bir kısmı fayda görmekle beraber, yeni GÖR hastalarının semptomlarının şiddetindeki azalmanın daha fazla olduğu saptanmıştır. Tedavi sonuçlarımız, Jones ve ark. yaptıkları GÖR tanılı erişkin hastalara PPi tedavisi başlayarak GÖRHEÖ skalası ile değerlendirdikleri çalışmalarıyla uyumlu idi (7). Başka bir çalışmada ise Woolf ve ark. göğüs ağrısı ve MVP'si olan 14 çocuk hastanın 12 tanesine oral anti asit tedavisi vermişler ve tedavi sonrası 12 çocuk hastanın da anti asit tedavisi ile ağrıları geçmiştir (1).

Çalışmamızda bazı kısıtlamalar mevcuttur. Kullandığımız GÖRHEÖ skalası Öncellikle erişkinler için geliştirilmiştir. Çocuk hastalar için buna benzer bir skalaya literatürde rastlanmamıştır. Ama hastalarımızın adölesan çağda ya da bu çağa yakın yaşlarda olmaları ve ölçek sorularının net, kolay olmasından dolayı GÖRHEÖ skalasının bu yaş grubuna da uyarlanıp kullanılabileceğini düşünmekteyiz. Mitral kapak prolapsusunun kız cinsiyette daha sık görülmesinden dolayı çalışmaya alınan hastaların çoğu kız hasta idi ve gruplar arasında istatiksel bir farklılık yoktu.

Smith ve ark., MVP'de göğüs ağrısının aslında köken olarak psikojenik olabileceğini iddia etmişlerdir (14). Gastroözofageal reflü hastalığının tedavisinin, göğüs ağrısının giderilmesinde etkili olsa da PPI'ların plasebo etkisi tamamen yok farz edilemez. PPI tedavisine yanıt veren tüm hastalar pediyatrik gastroenteroloji polikliniğine yönlendi- 
rilmiş olup, pediyatrik gastroenteroloji bölümü tarafından hastaların sadece 4 tanesinde daha ileri tetkik ve tedavi uygun görülmüştür.

Sonuç olarak, çocuklarda MVP gibi tanımlanmış bir kardiyak hastalık olduğunda bile, göğüs ağrısının gastrointestinal sistemden kaynaklanıyor olması daha olasıdır. Erişkinlerde ve çocuklarda, gastrointestinal sistemden kay-

\section{KAYNAKLAR}

1. Woolf PK, Gewitz MH, Berezin S, et al. Noncardiac chest pain in adolescents and children with mitral valve prolapse. J Adolescent Health 1991;12:247-50.

2. Fyfe DA, Moodie D. Chest pain in pediatric patients presenting to a cardiac clinic. Clin pediatr 1984; 23:321-4.

3. Spears PF, Koch KL. Esophageal disorders in patients with chest pain and mitral valve prolapse. Am J Gastroenterol 1986;81:951-4.

4. Vakil N, Van Zanten SV, Kahrilas P, et al; Globale Konsensusgruppe. The Montreal definition and classification of gastroesophageal reflux disease: a global evidence-based consensus. Am J Gastroenterol 2006;101:1900-20.

5. Modlin I, Hunt R, Malfertheiner P, et al; Vevey NERD Consensus Group. Diagnosis and management of non-erosive reflux disease-the Vevey NERD Consensus Group. Digestion 2009;80:74-88.

6. De Leone, A, Tonini M, Dominici P, et al; EMERGE Study Group. The proton pump inhibitor test for gastroesophageal reflux disease: optimal cut-off value and duration. Dig Liver Dis 2010; 42:785-90.

7. Jones R, Coyne K, Wiklund I. The gastro-oesophageal reflux disease impact scale: a patient management tool for primary care. Aliment Pharmacol Ther 2007; 25:1451-9. naklandığı düşünülen göğüs ağrııının tanısında anamnez ve fizik muayene birinci sırada olup, gerekirse ileri inceleme olarak pH metre ya da impedans (MII) kullanılmaktadır. Bu hastalara semptomatik tedavi başlanıp tedaviye yanıta göre karar vermek daha uygun bir tutum olacaktır. Sonuçlarımızı doğrulamak için daha büyük ölçekli çalışmalara intiyaç vardır.
8. Fox M. and Forgacs I. Unexplained (non-cardiac) chest pain. Clin Med 2006;6:445-9.

9. Sabri MR, Ghavanini AA, Haghighat M, Imanieh MH. Chest pain in children and adolescents: epigastric tenderness as a guide to reduce unnecessary work-up. Pediatr Cardiol 2003;24:3-5.

10. Diercks DB, Kirk JD, Amsterdam EA. Chest pain units: management of special populations. Cardiol Clin 2005;23:549-57.

11. Hammett RJ, Hansen RD, Lorang M, et al. Esophageal dysmotility and acid sensitivity in patients with mitral valve prolapse and chest pain. Dis Esophagus 2003;16:73-6.

12. Stanghellini, V, Armstrong D, Mönnikes H, Bardhan KD. Systematic review: do we need a new gastro-oesophageal reflux disease questionnaire? Digestion 2007;75:3-16.

13. Liker $H$, Hungin $P$, Wiklund, I. Managing gastroesophageal reflux disease in primary care: the patient perspective. J Am Board Fam Pract 2005; 18:393-400.

14. Smith MS, Doroshow C, Womack WM, et al. Symptomatic mitral valve prolapse in children and adolescents: catecholamines, anxiety, and biofeedback. Pediatrics 1989;84:290-5. 